\title{
XERODERMA PIGMENTOSUM WITH AFFECTION OF THE EYE*
}

BY

\author{
JOHAN SÆB $\varnothing$
}

NORWAY

IN the present article an account is given of a skin disease with ocular manifestations. At the beginning the skin disease was diagnosed as lentigenes and the eye-affection was suggested to be a melanoma bulbi. Observation of the clinical picture, however, and later familial investigations, gave clear evidence of a close connection between the two affections, and the condition became recognised as xeroderma pigmentosum (x.p.).

$\mathrm{X}$.p. belongs to the so-called actinic dermatoses, and is a rare disease in this part of the world. From the present work it clearly appears that in the initial stage of the disease the diagnosis may be difficult. Here the condition has been described from its first manifestation up to the fully developed clinical picture.

The term lentigenes has been made to describe from pinhead to lentil-seed-sized, brownish maculae, considerably darker than freckles. They may be sitting close together or. singly, and so they may be scattered all over the body. They are not congenital, but appear in the growing age. Lentigenes, in contrast to ephelides, are fairly uninfluenced by light.

A melanoma is, according to G. Miescher, a new-growth having the power of forming melanin. There are malignant and benign forms of these tumours. Distinction is further made between epidermogenic and cutaneous forms and those proceeding from the mucous membranes. Examples of epidermogenic melanomas are naevi spili, ephelides and lentigenes. "Mongolenfleck", and " Der blaue Naevus"' (Jadassohn) are cutaneous forms.

Melanomas also occur on the eye, and seem to have three sites of predilection : the corneal limbus, the lacrimal caruncle and the palpebral border. They may be malignant or benign. A benign melanoma may suddenly become malignant, and in these conditions it has been claimed that external factors (traumas) are of some importance in the transition to malignancy.

Schieck declares that the suspicion of malignancy should be specially strong where a macula suddenly begins to grow in an individual past the age of 30 years. Special attention should also be paid to tumours presenting marked pigmentary irregularities or

* From the Ophthalmological Clinic of the University Hospital, Oslo. Chief : Professor Birger Malling, M.D. Received for publication, January 29, 1948. 
unusually strong pigmentation. The case is a clear one where the tumour infiltrates a considerable part of the conjunctiva, and particularly in the presence of " Abklatsch-metastase," which is no rare occurrence. In these forms of newgrowths, other metastases are comparatively rare.

After this introduction, three cases of x.p. with ocular manifestations will be recorded.

\section{Case report}

Case I. M.L., a woman aged 17 years. Previously, she always had been in good health, apart from having " freckles" on her face, neck, arms and legs. As far as she could remember, the spots on her skin had always been there, but had presumedly increased in size and number during the last years. In summer they caused some discomfort, as she was sensitive to sunlight and apt to become. sunburnt. In the last years she had suffered from photophobia.

The patient had for several years had a dark spot in her right eye. Possibly it had lately grown somewhat larger. It had given no trouble, but now she wished to have it removed, mostly for cosmetic reasons.

The tumour was situated at the outer limbus of the right eye, extending about $3 \mathrm{~mm}$. into the cornea. As in pterygium a conjunctival fold was drawn after it. The tumour showed marked brownish pigmentation, but otherwise it resembled an ordinary pterygium. (To mention now that the appearance of the tumour was the same as that of a newgrowth developing several years later at the inner limbus of the same eye, is anticipating the sequence of events. See Fig. 8, Plate II.)

The location of the tumour at the temporal limbus may seem surprising. However, from the literature it is seen that whereas some authors insist that a pterygium is always situated on the nasal side others also claim the temporal side as a possible location. The brownish colour of the tumour was thought to have some connection with the otherwise hyperpigmentary condition of the patient.

The tumour was removed in the usual way, and on examination 2 months after excision, everything seemed normal. However, examination 2 years later, revealed a recurrence of the tumour. This is seen in Fig. 4, Plate II. A semilunar-shaped tumour was seen at the temporal limbus. At its widest it was about $4 \mathrm{~mm}$. and extended over half of the corneal circumference, from " 6 to 12 o'clock." The essential part of the tumour was lying in the cornea. The outward transition from the conjunctiva was even. Prominence was about $1.5-2 \mathrm{~mm}$. , and it terminated in a greyish-brown wedge 
under and into the corneal ephithelium. In the middle there was a cystic bulging, greyish-brown and with some darker parts. It was richly vascularized, moderately hard and not movable against the underlying tissue. No ulceration was present. A slit-lamp examination revealed the inner border of the tumour as a greyish-brown wedge, corresponding to Bowman's membrane. There was a strong admixture of brown pigment, and brown pigment-dust was seen in the cornea beyond the tumour proper. Otherwise the right eye appeared to be normal. No pathological changes in the left eye. Visual acuity : $5 / 10$ o.dext., $5 / 5$ o.sin.

This patient, accordingly, presented a dark brown, unevenly pigmented tumour at the corneal limbus, evidently a recurrence after the tumour removed 2 years earlier, which seemed to be steadily invading the cornea. Appearance and course indicated malignancy and the probability of melanomalignoma.'

The patient was admitted to the Ophthalmological Clinic of the University Hospital, Oslo, for observation and treatment. The - report of her eye-condition from this clinic corresponds to the description above. W.R., v. Pirquet negative. Sedimentation rate $5 \mathrm{~mm}$. The patient was examined at the Dermatological Clinic of the University Hospital with the following result: "The skin over the face, the neck, and to less degree over the extremities shows pronounced lentigenes. This skin condition represents a special form of pigment-naevi and defies treatment. It is reasonable to see her melanoma at the corneal limbus in relation hereto." In connection with this description, reference is made to Fig. 2, Plate I, and Fig. 7, Plate II, clearly illustrating the changes in the skin. In Fig. 1, Plate I, the skin-condition is specially distinctive.

Before proceeding to discuss the therapy for the eye-affection in this special case, it may be justifiable to make some comments on the treatment of melanomas in general.

The treatment of benign melanomas or naevi pigmentosi is essentially of cosmetic nature. For fear of malignancy some authors recommend the removal of any naevus. This may be slightly exaggerating the danger. But naevi occurring at an advanced age and showing irregular or very strong pigmentation, and particularly when growth commences after repeated irritation should be removed. Excision in normal tissue is recommended in flat, scarcely infiltrated growths. Electro-coagulation is also considered effective in such cases, whereas X-ray treatment is of no use.

In melanomalignomas excision has gone somewhat into the background. X-ray and radium treatment, electrolysis and diathermo-coagulation being preferred. The two latter methods 


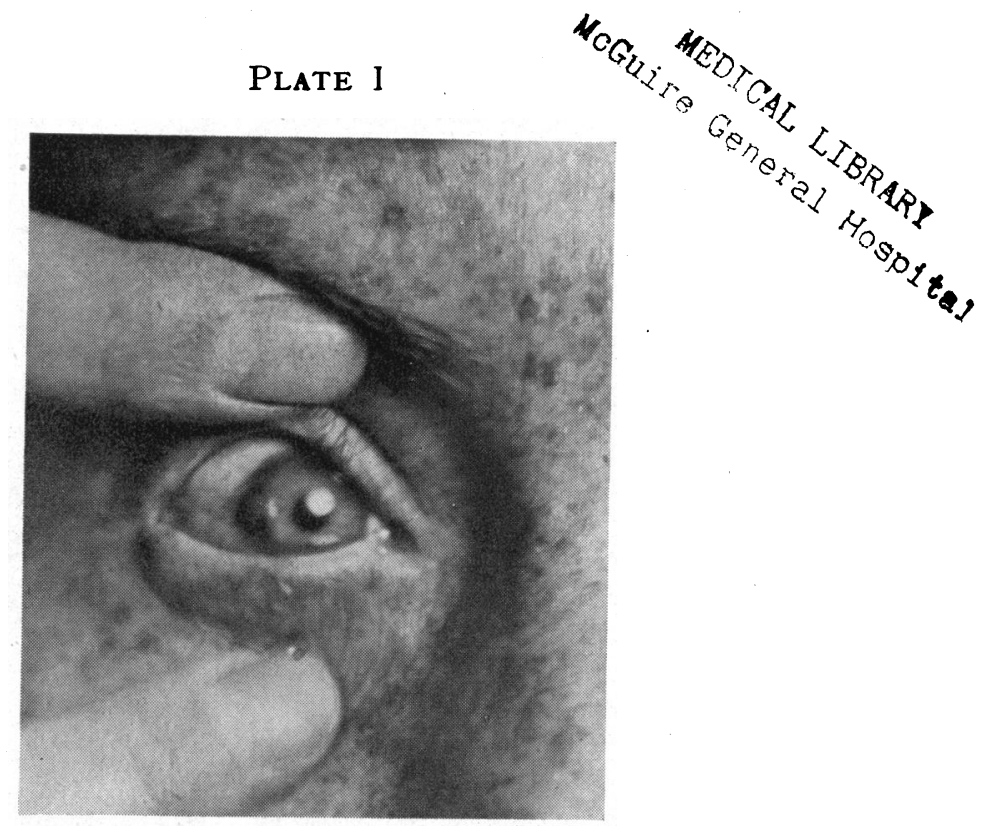

FIG. 1.

Xeroderma pigmentosum. Skin condition. Tumour at the limbus. Case I, M.L.. aged 19 years.

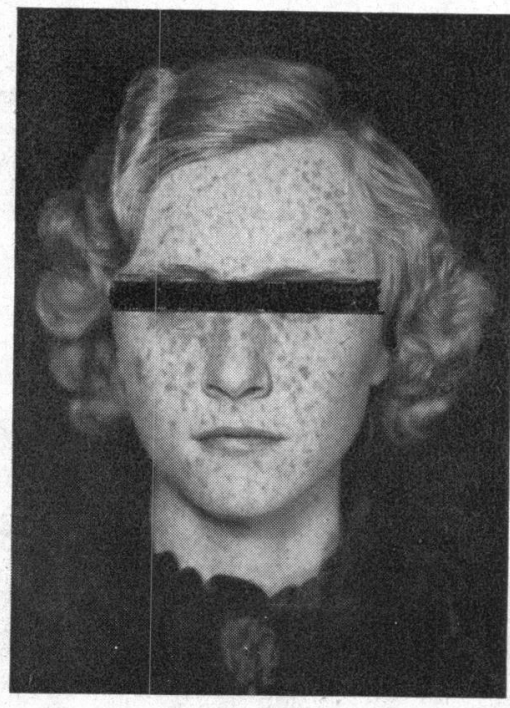

FIG. 2.

Xeroderma pigmentosum. Case 1 , M.L., aged 19 years.

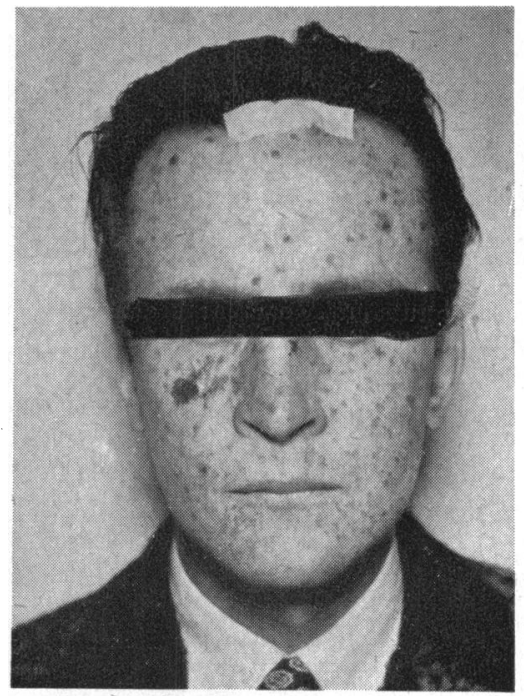

FIG. 3.

Xeroderma pigmentosum. Case 2 , A.L., aged 32 years. 


\section{Plate II}



FIG. 4.

Xeroderma pigmentosum. Tumour at the limbus. Case 1, M.L., aged 19 years.

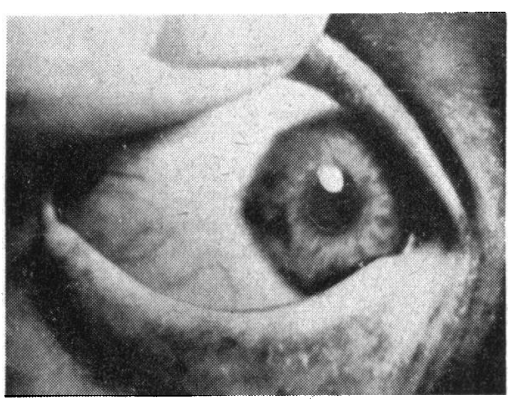

FIG. 5.

The same tumour two months after treatment with $\mathrm{X}$-rays.

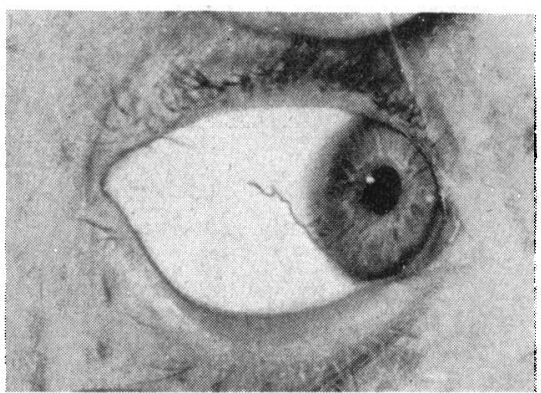

FIG. 6.

The same eye four months after treatment.

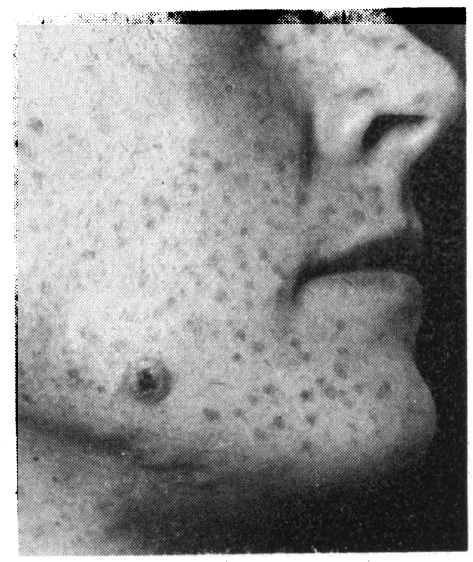

Fig. 7.

Xeroderma pigmentosum. Malignant tumour on the skin of the jaw. Case

1, M.L., aged 25 years.

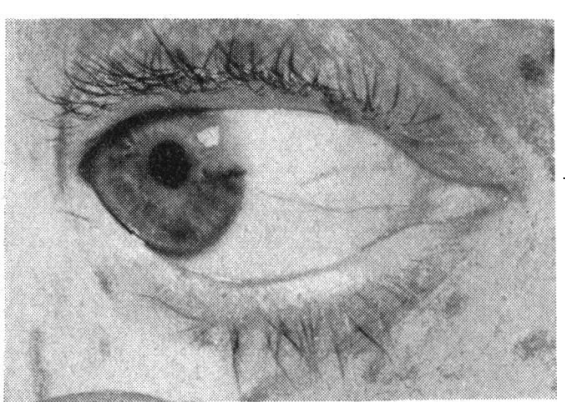

FIG. 8

New tumour of the inner limbus. Case 1, M.L., aged 27 years.



FIG. 9.

Xeroderma pigmentosum. The shoulder region. $X$ : malignant new growth. Case 2, A.L.
용

蛋 


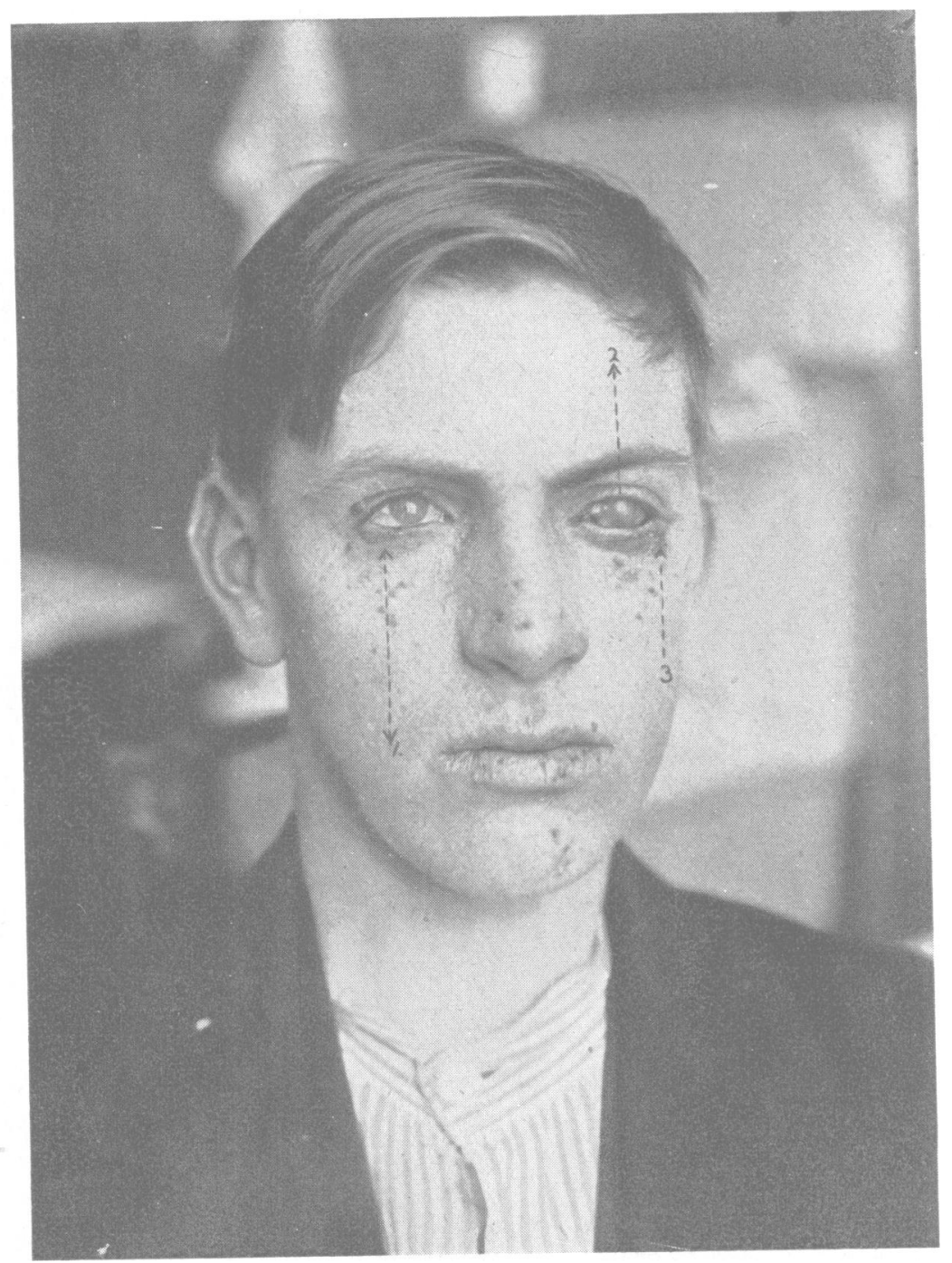

FIG. 10.

Xeroderma pigmentosum. Case 3, A.G., aged 18 years. 1, Whitish tumour at limbus. 2, Tumour corneal. 3, Carcinoma cutis. 
are considered the safest. Lately, however, this conception has been revised in favour of the X-ray-radium treatment. Evans and Leucutica (1931) treated 21 growing naevi, possibly already malignant, i.e., of a nature similar to the one described here, with massive X-ray doses, with excellent results in all cases.

It is possible, as mentioned above, that our case of melanoma bulbi should be regarded as a melanomalignoma. The excision of a piece of tissue for diagnostic purposes might have been desirable, but was hardly advisable. At the clinic there was some hesitation before the choice of therapy, and enucleation was discussed. However, it was decided to try X-ray treatment before resorting to this radical intervention. In the course of $29 / 9-21 / 10,1938$, the patient received a total of $4,000 \mathrm{r}$ : single doses of $200 \mathrm{r}$. The eye was irradiated tangentially and laterally. The field of irradiation was limited by glass tubes and the skin protected by lead rubber.

Distinct hyperaemia developed during the treatment. In the course of one month, the tumour commenced to subside. About 2 months after institution of the treatment the tumour had nearly disappeared. This clearly appears from Fig. 5, Plate II, showing some pigmented spots at the site of the tumour. After another 2 months practically all traces of the tumour had vanished, see Fig. 6, Plate II. The corneo-scleral border was somewhat blurred, and dilatation of an episcleral vessel was noticed. Slit-lamp examination revealed some fine vascular shadows in the cornea and some fine brown dust in the epithelium. Otherwise the eye appeared normal. Visual acuity $5 / 5$.

The patient accordingly showed no recurrence during 3 years of observation. The illustrations clearly show the effectivity of the local X-ray treatment of the tumour. It might, therefore, be of some interest to our colleagues, meeting similar cases, to note doses and mode of application.

At this time the condition was believed to represent a melanomalignoma bulbi, intimately connected with the lentigenes of the skin. Later investigations proved the correctness of this connection, but on a basis different from what had been presumed. Complications from the skin, and not least some familial investigations that were made, proved the fundamental disease to be xeroderma pigmentosum.

About 8 years after the removal of the first " pterygium " (the patient now aged 25 years), a pea-sized tumour developed on her right cheek, see Fig. 7, Plate II. Ulceration started in the centre of the tumour, and the ulcer could not be made to heal in spite of treatment. The patient was referred to the Roentgen-Radium Institute of the University Hospital with the diagnosis : carcinoma 
basocellulare. The following is seen from her chart: "On right cheek, somewhat above the mandibular margin, there is an oval ulceration, somewhat larger than a pea, with elevated borders and a central part covered with a crust." Biopsy proved : carcinoma basocellulare.

The patient received radium treatment. Tube preparation : 2 tubes of $5 \mathrm{mgm}$. RaE. Filter : $0.5 \mathrm{~mm}$. platinum. Radium-skindistance : $5 \mathrm{~mm}$. Intensity in $\mathrm{r}$. per hour : 66.5 for 54 hours $=$ $3.600 \mathrm{r}$.

The result of treatment was good, only a whitish scar being left 4 months later.

At this time the patient observed another tumour on her neck at the insertion of the sternocleidomastoid muscle. The tumour was the size of a hazel-nut, was hard and non-sensitive. Biopsy was made and the diagnosis read : carcinoma with regressive changes. The patient was treated with radium : 3 radium needles of $5 \mathrm{mgm}$. RaE. Filter: $1 \mathrm{~mm}$. platinum. Intubation for 42 hours. The result was good. But already a few weeks later a gland, the size of the kernel of a nut, developed in the fossa supraclavicularis on the same side, slightly lateral to the treated area. The gland was extirpated and examined : little differentiated carcinoma.

Later the patient has been treated at the Norwegian Radium Hospital, Oslo, for similar tumours of the skin. Here she has received treatment with $\mathrm{X}$-ray, and the effectivity has always been good. At the present time she has an ulcer on the back of her hand consequent to radium-treatment of a tumour in this place. Otherwise her general condition was good, and she was continuing her usual work. She was now 27 years old. On renewed examination her left eye was still seen to be normal. But at the nasal limbus of her right eye there was a dark spot, similar to the "pterygium" that was removed 10 years earlier, see Fig. 8, Plate II. There was a triangular brownish area, reaching from the limbus and about $3 \mathrm{~mm}$. into the cornea. As in pterygium, a fine conjunctival fold is stretching toward the spot. In slit-lamp examination the spot was seen to consist of fine pigment-particles, situated in the epithelium. Otherwise the eye was normal. Visual acuity $5 / 5$.

On questioning the patient about her family it was learned that her brother is suffering from a similar disease. He has also been examined.

Case 2. A.L., a man aged 32 years. As long as he can remember, he has had brown spots on his face, neck and extremities, similar to those seen in his sister. (See Fig. 3, Plate I.) They had grown somewhat larger and darker in the course of 
years. He was very sensitive to sun-light and easily became sunburnt. At times he suffered from photophobia. The above mentioned parts were thickly covered with irregular brown maculae, from pin-head to lentil-seed size. In some places the spots were flowing together into larger irregular fields, as on the right cheek and on the forehead. These parts were brownish-black. A great part of the maculae resembled freckles. The skin over these parts was atrophic with numerous cicatricial spots. Fig. 9, Plate II shows the region of the shoulder, with a little malignant newgrowth. The changes in the skin were identical with those of his sister.

At the age of about 27 years a tumour developed on his neck and was effectively treated with $\mathrm{X}$-ray. Some time later an ulcer on his left ear was healed by radium treatment. Since then new ulcers or tumours often have appeared on his eyebrow, cheeks, on his forehead, at the root of his hair (Fig. 3, Plate I), and on his arm. $\mathrm{X}$-ray or radium treatment has been given with good result. Otherwise the patient was feeling well and had been working most of the time.

At the Norwegian Radium Hospital these new-growths had also been interpreted as malignant naevus-cell tumours, developed on basis of x.p.

On examination of the patient's eyes, changes were found, that must undoubtedly be connected with the skin-disease.

O.dext. Close to limbus, corresponding to " 9 o'clock," a small, distinctly red spot in the conjunctiva was seen, about $2 \mathrm{~mm}$. in diameter. On slit-lamp examination it was seen to consist of a number of local dilatations of episcleral vessels. The vascular spot had been noticed for years by the patient. Otherwise the eye was normal. Visual acuity $5 / 5$.

Familial Examination gave the following result (see p. 404).

1st generation. Photographs of the two, who died at an old age, showed normal pigmentation of the skin.

2nd generation. Photographs of all these, who also died old (aged 76, 90, 83, 76 years 1 ), showed normal colours of the skin.

3rd generation. These two were first cousins, and were now 58 and 57 years old. They had both normal skin-pigmentation.

4th generation. This includes 7 children in a marriage between first cousins. No. 3 is the patient A.L., and No. 5 the patient M.L. As to No. 4, K.L. (29 years old) there was some doubt. On her face, especially on the nose and proximal parts of the cheeks, there were some brownish spots resembling those seen in the two patients. The rest of her body showed normal pigmentation of the skin. The brownish spots were not distinctly differentiable from 


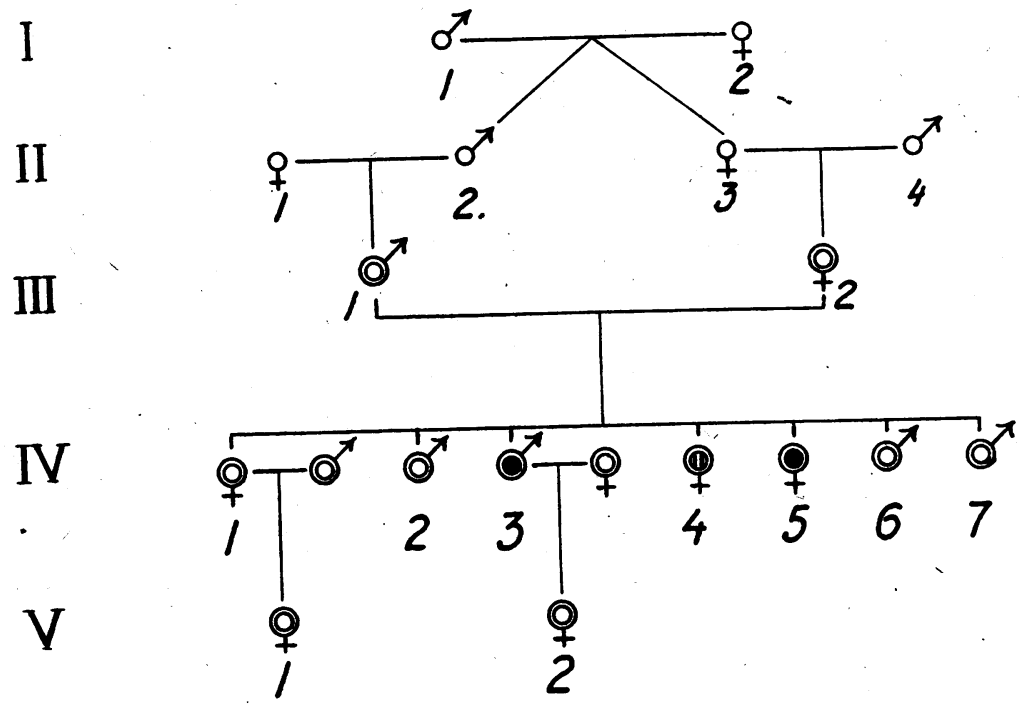

Fig. 1.

Pedigree demonstrating the consanguinity of the parents of the patients affected with xeroderma pigmentosum. (Gen. IV : No. 3 : A.L., No. 4 : K.L., No. 5 : M.L.)
(a) Examined.
(2) Affected.
(1) Probably affected.

ordinary freckles, but with our present knowledge of the disease in her family, the spots will naturally be suspected to be of the same character. Nos. 1, 2, 6 and 7. from 4th generation had normal skin pigmentation. The youngest one was 20 years old. No. 1 had a husband to whom there was no blood relationship, and these had one child ( 2 years old). Both of them had normal skinpigmentation. No. 2 was unmarried, and so were Nos. $4,5,6$ and 7 . No. 3, the patient A.L., was married to a woman to whom there was no blood relationship. She and their 2 years old child seem as yet to be normal.

The familial incidence suggested that the disease was hereditary, and in all probability due to a recessive gene. The fact, that the affected individuals occurred in a consanguineous marriage was a strong indication thereof. This conception is in accordance with earlier results. Thus Bering and Barnewitz: Handbuch der Haut- und Geschlechtskrankheiten (1932), found that $17 \cdot 1$ per cent. of the affected individuals occurred in consanguineous marriages. This view is shared by Karl Zieber in his: Lehrbuch und Atlas der Haut- und Geschlechtskrankheiten (1928). 
Ingolf Schiótz, M.D., Oslo, has most kindly brought to my notice that a patient suffering from x.p. and affections of the eyes was at the Dermatological Clinic of the University Hospital in Oslo in 1920. Detailed information about the patient has been obtained from this source.

Case 3. A.G., male. His journal informs us that he was examined by an ophthalmologist at the age of 10 , and that a whitish blister as big as a pin-head had been present at the inner corneal limbus of the left eye for a period of about a year. This blister had slightly increased in size. The examination gave the following results :

Left eye. There is congestion of the conjunctival and episcleral vessels of the inner part of the eye. At the inner corneo-scleral limbus there is a blu ish-white, hard, insensitive, cauliflowerlike tumour, about 1-2 mm. in over the cornea. The eye is otherwise normal. Visual acuity $5 / 6$.

Right eye is normal.

The ophthalmologist considered the tumour at that time as benign, but wished to excise it all the same. This was not done, however, and the patient was lost sight of until he was 18 years old. The clinical picture was then quite changed, and the patient was sent to the Dermatological Clinic of the University Hospital, Oslo. Here he stated that the above-mentioned tumour, in the course of the last seven years, had grown to cover the whole eye, which became almost blind at the age of 16 years. The patient further stated that at the age of 9-10 years, the skin of his face had become uneven in places, and that at times the lumps had become sores. Some years later, the lid borders of both eyes became sore. His condition grew worse during the summer.

The Dermatological Clinic of the University Hospital, Oslo, gave the following description of the case $(17 / 3 / 1920)$. See Fig. 10, Plate II. Large and small telangiectases, angiomas and naevi are now visible in the face, on the chin, the neck, the nose and less marked on the forehead. These naevi are raised above the level of the skin, and have a yellow, wart-like surface. This is especially marked on the left lower lid and on the ear. Between these telangiectases and angiomas, small scar-like atrophies are visible. The lower lid is sore and cracked and has numerous telangiectases. On the left lower lid, there is to be seen a crustcovered ulceration, limited by, a clearly infiltrated zone.

The patient was examined at the Ophthalmological Clinic of the University Hospital, with the following result : The extraordinary eye disease presented by A.G. has not hitherto been " seen at the clinic. His disease must be considered a malign-tumour-like new- 
growth, epithelioma corneae, perhaps originating in the limbus corneae."

Left eye. Below the external canthus, there are some crustcovered uneven sores. The edges of the lids are thick and red with sores and crusts. The conjunctival vessels are moderately congested. Numerous blood vessels are visible in the conjunctiva and these invade the cornea. Together with the neighbouring parts of the sclera, the cornea forms a kind of proliferating tumour-like mass, with an uneven, partly rough surface, greyish-red in colour. This mass seems to form a thin shell about $2 \mathrm{~mm}$. thick which covers cornea and the nearest parts of sclera to an extent ca. $15 \mathrm{~mm}$. in diameter. Visual acuity: Hand movements at $\frac{1}{2} \mathrm{~m}$. Light projection good.

Right eye. The lid borders are thick and partly covered with crusts. On the upper eyelid can be seen a dark " wart" ca. $2 \mathrm{~mm}$. in diameter. The conjunctival vessels are congested. At the outer corneo-scleral limbus, there is a small whitish pinguecula-like condition and a fair number of vessels invade this. Visual acuity : $5 / 5$. At the beginning of his stay in hospital, the patient was given a light cure, and his condition became clearly worse during this time. Later on, he was treated with epilation, mercury oxide ointment and silver nitrate, without any certain effect.

As the process was advancing in the left eye, enucleation was advised. However, he refused to undergo the operation, and returned to his home after a stay of $1 \frac{1}{2}$ months.

During his stay in hospital, excision of a piece of tissue from the ulcer on the left inferior palpebra was excised for microscopical examination. The diagnosis was carcinoma.

At our request the clergyman in his home district has told us his later history as follows: One year after his return home, the left eye had to be excised because of the pain it gave him. After a second year, the right eye had to be excised for the same reason. The malignant new growths spread gradually over the whole face, so that he became quite disfigured and he died at the age of 21 years.

Familial investigations in this case gave no result of special interest. The patient was the illegitimate son of parents who are now both dead. No consanguinity between the parents.

\section{Discussion}

Here the disease xeroderma pigmentosum has been followed from so early a stage as to defy certain recognition on a basis of the findings in evidence, and up to the fully developed clinical picture with serious complications. When additionally, as in cases 1 and 
2 , the recessive mode of heredity must be considered established, the diagnosis must be correct.

In one of the above mentioned cases, malignancy was first evidenced in a tumour of the eye. If malignancy had proceeded from the pigmented spots on the skin, the diagnosis might have been established at an earlier stage.

X.p. is a rare disease in this country. In 1939, Professor Danbolt of Oslo demonstrated such a case at the Norwegian Dermatological Society. The disease is more frequent in southern countries. (See Junes's work from Tunisia.)

The disease is congenital and develops under the influence of light in the course of the first years of life. According to Bering and Barnewitz, different stages are recognisable : 1, Hyperaemicinflammatory stage; 2 , stage of brown warts and excrescences; 3 , formation of malignant growths.

The disease often includes ocular manifestations. Ectropion may be seen subsequent to palpebral affections, pigmented conjunctival tumours and teleangiectases. Papillomas are occasionally seen at limbus corneae and in the cornea proper. The nature of these occurrences is often malignant, and they will propagate to other parts of the eye, with resulting blindness.

As a rule x.p. is a serious disease, and the patients often die at an early age. However, the course may be protracted over years and decades, but the prognosis is always grave.

In the two cases first described, the course of the disease seems fairly protracted. Its serious character, however, is seen from the frequent formation of malignant new-growths, and from the metastasis to a gland in the patient M.L., case 1.

In the two patients, cases 1 and 2 , the disease became manifest at a comparatively advanced age, and this may agree with the relative benignity in these cases. Literature shows that the earlier the manifestation of the disease, the greater the malignancy.

As seen from the first two cases of X.p., local X-ray and radium treatment gave an excellent effect. Accordingly it is important to detect the malignant new-growths at an early stage in order to get them treated before they spread to other parts of the body. The constant re-appearance of malignant new-growths both in the eyes and in different places in the skin was arrested by this treatment in its deleterious activity. After surveying the course of the disease, we can now assume that malignancy was already present at the age of 17 in case 1 , and of 27 in case 2 . These patients are now aged 27 and 32 respectively and continue in good health and are doing full-time work.

Case 3 is well suited for a comparison from this point of view 
with the two mentioned above, as the clinical course seems to have been similar. The correct. and serious nature of the disease was overlooked in both cases 1 . and 3 , as both of them started with relatively innocent looking tumours in the eyes and even the changes in the skin showed so few of the characteristics of the disease during the first years that they did not give sufficient grounds for an x.p.-diagnosis.

In case 1 , a pterygium-like tumour developed in the right eye from the age of 15 years. The pigmented spots in the skin were thought to be freckles. A tumour in the eye was excised when the patient was 17 , but already at the age of 19 years she had a certain relapse. This was taken to be a melano-malignoma. Also then the pigmented spots in the skin were understood to be lentigenes. Not until the patient was 25 years old the constantly re-appearing of malignant new-growths in the skin had been proved malignant by microscopical examination, and the disease was finally diagnosed as x.p. Proof of recessivity further supported this diagnosis.

In case 3 a tumour at the inner limbus of the left eye was found at the age of ten. The tumour was whitish and was first taken to be benign, and not considered in the conjunction with the other symptoms from the patient's skin. It was only when the patient was 18 years old that the malignancy of the tumour and its real nature were understood, and also in this case, in connection with closer examinations of malignant new-growths in the skin. The tumour in the eye had now spread over the whole cornea and neighbouring parts of sclera. At the age of 16 years; the eye was nearly blind. There was now a little whitish tumour at the limbus corneae of the right eye. This spread over the right eye in the same fashion until that eye also became blind. Both eyes had to be excised. Later on, malignant new-growths spread over the whole face, and the patient died aged 21 years.

Thus we see that after a relatively quiet period from $10-18$ years of age, with changes in the eye which were considered relatively. harmless, the disease took an exceedingly malignant course. In this case, too, there was now no doubt that the fundamental disease was x.p.

If we now compare the results of the treatment of these three cases, which were very much alike in their clinical course before treatment started, the question naturally arises : Could the development of malignant new-growths have been stopped by early applied $\mathrm{X}$-ray or radium treatment also in this third case?

As already mentioned, these three cases show that the diagnosis x.p. may be difficult in the early stages of the disease, which is rare in our country. This is also in agreement with the declaration 
from the Eye Clinic at the University Hospital, where it has been stated that no case of this strange eye disease had yet been seen there.

There is reason for supposing that the course of the disease in our country is less rapid than we usually find in case reports from southern countries. In one of our cases we have also seen that treatment by light had a distinctly deleterious effect.

It is thus of importance to see that this disease also occurs in northern countries, and should be kept in mind. The result will be that even in cases of relatively benign looking tumours in the eyes, in conjunction with pigmented spots in the skin, the patients must be regularly controlled.

At a final examination of our patients, case 1 showed a new pterygium-like tumour of the same kind as the first one removed see Fig. 8, Plate II), and case 2 showed pigmented spots and telangiectases in the conjunctiva. Both patients are therefore under control. In cases 1 and 2 , familial investigations show that the disease is due to a recessive gene. Apart from local treatment eugenic measures must be taken to prevent the spread of this serious disease in the family. The members of the family should be instructed concerning the mechanism of heredity, and especially concerning the influence of consanguineous marriages.

\section{Summary and conclusion}

The author reports the cases of a sister and brother and a case from another family with xeroderma pigmentosum and affections of the eye.

A brief account is given of x.p. and of melanomas in general and their treatment.

The difficulty of recognising x.p. at the initial stage is mentioned. In the first case the correct diagnosis was only established after years of observation. The ocular tumour in this patient, a recidivation after a removed pterygium-like condition, was thought to be a melano-malignoma and the skin-disease to be lentigenes.

During the years of observation, at the age of 17-27 years, constant re-appearing of malignant new-growths in different parts of the skin and metastasis to a gland were found. The malignancy of these were verified by microscopical examination. Further examination of the patient's family revealed the recessive nature of the condition, and made it clear that the fundamental disease was $\mathrm{x} . \mathrm{p}$.

The brother of the first patient has the same disease. The first malignant new-growth appeared here at the age of 27, and later he has had many of them at various places of the skin. This patient 
also presented symptoms from his eyes. Naevi and telangiectases were seen in the conjunctiva.

The excellent result of X-ray or radium treatment in both of these cases is shown. The effect of both of them seems equally good. Mode and doses are specified.

Both patients are otherwise feeling well, and are still able to attend their usual work, and are now aged 27 and 32 years respectively.

The author further describes a third case of x.p. from another family. The affection of the eye appeared at the age of 10 years as a little whitish tumour of relatively benign appearance at the corneal limbus of the left eye. On renewed examination, at the age of 18 , the tumour had infiltrated the whole cornea and parts of the sclera, and the eye was nearly blind. In the right eye there was a little whitish pinguecula-like tumour at the limbus. New-growths were found in the skin, and the malignancy was verified microscopically. Only then was the disease recognised as x.p. This patient was treated with silver nitrate and mercury oxide ointment. He also had a light-cure, which had a distinctly deleterious effect. Both eyes were blind at the age of 20 years, and were enucleated. The new-growths spread over the whole face, and the patient died when aged 21 years.

The result of the treatment in this case is compared with the results in the two first cases, 'and the question is raised whether a similar treatment with X-ray or radium might not have given a more favourable result. The clinical pictures were much alike in all three cases before treatment was started.

$\mathrm{X} . \mathrm{p}$. is rare in northern countries, the symptoms are vague in the beginning, and it probably takes a more protracted course here than in southern countries.

Special emphasis is laid on the fact that this disease must be kept in mind even in cases of seemingly benign tumours in the eyes when they appear in conjunction with pigmented spots in the skin.

Finally, mention is made of the eugenic measures that ought to be taken in order to prevent the spread of this serious, hereditary disease.

\section{REFERENCES}

BERING, FR, and BARNEWITZ, J. (1932)-Handbuch der Haut-und Geschlechtskrankheiten. Aktinische-Dermatosen. p. 128.

Dan bolt, Niels (1939)-Xeroderma pigmentosum. Acta derm. venereol. (Demonstration) Vol. XX, p. 323.

Evans, William A. and Leucutica, T. (1931)-The Treatment of Melanotic Tumours of the Skin: Pigmented Moles and Malignant Melanomas. Amer. Jnl. Roentgenol., Vol. XXVI, p. 236, 
JUnÈs, E. (1925)-Xeroderma pigmentosum avec lésions oculaires. Le X.p. en Tunésie. Arch. d'Ophtal., Vol. XLII, p. 193.

Miescher, G. (1933)-Melanom. Sonderdruck aus Handbuch der Haut-und Geschlechtskrankheiten. Herausgegeben von J. Jadassohn. Springer, Berlin. Vol. XII, Part 3.

Schieck, F. (1931)-Die Erkrankungen der Conjunctiva, Cornea und Sclera, Kurzes Handbuch der Ophthal. Springer, Berlin. Vol. IV.

ZIEBER, KARL. (1938)-Lehrbuch und Atlas der Haut und Geschlech tskrankheiten, p. 203.

\section{THE PRESENT STATE OF THE PROBLEM OF RETINITIS PIGMENTOSA*†}

B Y

\section{BIRó}

BUDAPEST

AfTER the clinical characters of retinitis pigmentosa had been defined by the papers of van Trigt, Ruete, von Graefe, Donders and Leber, research turned towards the morphology and histology (Stock, Suganuma, Ginsberg, Koyanagi, Schieck). Later research was directed toward the biological relations of the disease and the field of enquiry was considerably extended by the discovery of endocrinological factors. Investigations of possible connections between retinitis pigmentosa and the pituitary, thyroid, gonads and adrenals did not-all lead to results of lasting value. But even the negative results were important, and the possibilities of endocrine involvement are now limited to the pituitary and the surrounding parts of the diencephalon.

During the latter half of the 30's when the part played by the pituitary and the hypothalamus became obvious, investigations turned to the question of inheritance.

The symptoms and groups of symptoms which so frequently are associated with pigmentary degeneration of the retina and originate. within the pituitary and diencephalon suggest that these areas must play some part in the origin of the disease. The general metabolic disturbances, alterations of the water and salt metabolism, the low body temperature, the hypotony and cholesterinaemia (Lauber, Levy-Wolff) should be ascribed to factors within the diencephalon, and the inhibition of growth, adiposity, polyuria, syndactyly, genital hypoplasia, or polydactyly (Laurence-Moon-Biedl syndrome) are of pituitary origin. Deafness, dumbness, epilepsy, acrocyanosis, Raynaud's gangrene, are

\footnotetext{
* From the Ophthalmological Clinic No. 1, University of Budapest.

+ Received for publication, November 20, 1947.
} 